\title{
\begin{tabular}{l|l} 
Mibraries & DSpace@MIT
\end{tabular}
}

\author{
MIT Open Access Articles
}

Rigid Hydrophilic Structures for Improved Properties of Conjugated Polymers and Nitrotyrosine Sensing in Water

The MIT Faculty has made this article openly available. Please share how this access benefits you. Your story matters.

Citation: VanVeller, Brett, Koji Miki, and Timothy M. Swager. “Rigid Hydrophilic Structures for Improved Properties of Conjugated Polymers and Nitrotyrosine Sensing in Water." Organic Letters 12.6 (2010): 1292-1295.

As Published: http://dx.doi.org/ 10.1021/ol1001768

Publisher: American Chemical Society (ACS)

Persistent URL: http://hdl.handle.net/1721.1/74231

Version: Author's final manuscript: final author's manuscript post peer review, without publisher's formatting or copy editing

Terms of Use: Article is made available in accordance with the publisher's policy and may be subject to US copyright law. Please refer to the publisher's site for terms of use. 


\section{Rigid Hydrophilic Structures for Improved Properties of Conjugated Polymers in Water}

\begin{tabular}{|c|c|}
\hline Journal: & Organic Letters \\
\hline Manuscript ID: & Draft \\
\hline Manuscript Type: & Communication \\
\hline $\begin{array}{r}\text { Date Submitted by the } \\
\text { Author: }\end{array}$ & \\
\hline Complete List of Authors: & $\begin{array}{l}\text { Swager, Timothy; Mass. Inst. of Tech., Chemistry } \\
\text { VanVeller, Brett; Massachusetts Institute of Technology } \\
\text { Miki, Koji; Kyoto University, Energy and Hydrocarbon Chemistry }\end{array}$ \\
\hline
\end{tabular}

\section{Sanuscript central}




\title{
Rigid Hydrophilic Structures for Improved Properties of Conjugated Polymers in Water
}

\author{
Brett VanVeller, Koji Miki, and Timothy M. Swager* \\ Department of Chemistry, Massachusetts Institute of Technology, Cambridge, \\ Massachusetts 02139 \\ tswager@mit.edu
}

Received Date (will be automatically inserted after manuscript is accepted)

\section{ABSTRACT}

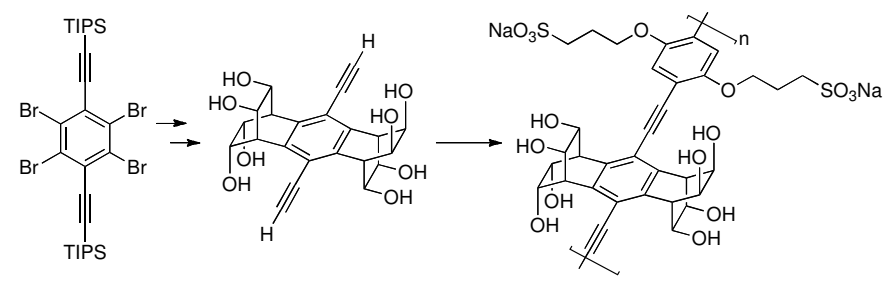

This paper describes the synthesis of a hydrophilic monomer bearing a three-dimensional noncompliant array of hydroxyl groups that prevents water driven aggregation of hydrophobic poly( $p$-phenylene ethynylene) polymer backbones.

Fluorescent conjugated polyelectrolytes (CPEs) are made water soluble by pendant ionic functionalities along the polymer backbone. CPEs have seen application in a variety of chemical and biological sensing schemes ${ }^{1}$ because the intra- and interchain migration of excitons along the polymer backbone results in the amplification of fluorescence signals relative to small-molecule fluorophores. ${ }^{1 \mathrm{a}, 2}$ However, the rigid hydrophobic main chains of CPEs are prone to interpolymer $\pi-\pi$ interactions leading to self-quenching and reduced luminescence. ${ }^{3}$ Supramolecular and macromolecular approaches to mitigate these effects have been developed that effectively isolate polymer chains from each other. ${ }^{4,5}$ However, these strategies can result in large interpolymer separation that can reduce energy transfer between chains, which is the basis of some transduction schemes. ${ }^{1 b}$

The three-dimensional, noncompliant structure of iptycene-type monomers (2, Figure 1) has been shown by our laboratory to prevent strong quenching interactions between polymer chains while still promoting productive interpolymer energy transfer necessary for amplification. ${ }^{6}$ We hypothesized that monomer $\mathbf{1}$, with its three dimensional hydrophilic architecture, might impart the same properties to water soluble polymers as $\mathbf{2}$ does in nonpolar media.

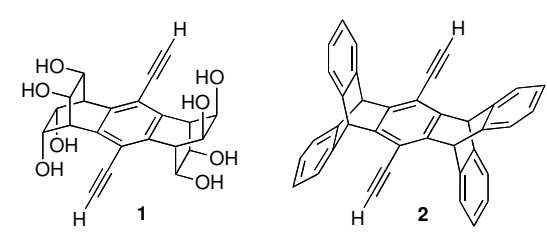

Figure 1. Three dimensional monomers

The synthesis of $\mathbf{1}$ began with $p$-bromanil (3); double addition of TIPS acetylide to 3 followed by $\mathrm{SnCl}_{2}$ reductive aromatization provided $4 .^{7} \mathrm{We}$ envisioned the three dimensional carbon framework might be established in one step via a double aryne-cycloaddition protocol. ${ }^{8}$ In the event, addition of $n$-BuLi to dienophile precursor 4 at -45 
${ }^{\circ} \mathrm{C}$ produces a benzyne intermediate after initial lithiumhalogen exchange. This putative dienophile underwent [4+2] cycloaddition with $\mathbf{5}^{9}$ to provide a mixture of $\mathbf{6}-\mathbf{a n t i}$ and 6-syn cycloadditon products in a ratio of 1.7:1. The reaction was evaluated under a variety of solvent and temperature conditions (a more detailed discussion can be found in the Supporting Information), but the ratio of isomers varied only slightly. The isomers were not easily separated so the mixture was carried on to the next step; however, sufficient quantities of 6-anti could be isolated to confirm the stereochemistry by X-ray crystallography (Scheme 1). The structure of 6-syn was determined from a dioxo-diosmium bridged species isolated in a subsequent step (vide infra Scheme 2). Despite a modest yield, this procedure creates considerable complexity in a single step. Further, this transformation can be performed on multigram scales $(>5 \mathrm{~g})$.

Scheme 1. Synthesis of the carbon framework
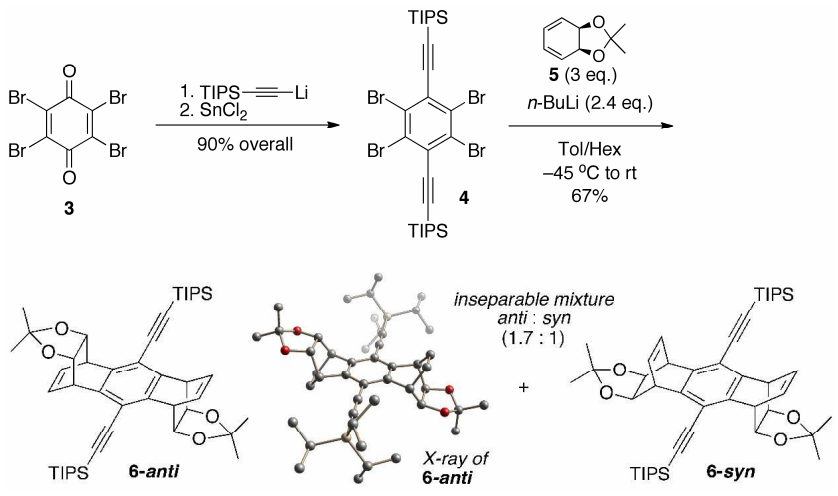

Modeling studies suggested the double dihydroxylation of 6 would occur on the less hindered face of the alkene in $\mathbf{6 -}$ anti/syn to produce the corresponding isomers 8-anti and 8-syn (Scheme 2). Unfortuantely, all attempts with a variety of NMO mediated osmium tetroxide dihydroxylation conditions (Upjohn process) ${ }^{10,11}$ showed no conversion of starting material. However, ${ }^{1} \mathrm{H}$ NMR analyses of the crude reaction mixtures revealed the amount of 6-syn diminished relative to 6-anti with increasing $\mathrm{OsO}_{4}$ loadings. To investigate this observation further, a reaction using a stoichiometric amount of $\mathrm{OsO}_{4}$ was performed and 7 was obtained. While dioxo-diosmium type species are known, ${ }^{12}$ the cis-dioxo variant $\mathbf{7}$ demonstrates remarkable stability in a variety of solvents and can be purified by silica gel chromatography. The steric bulk surrounding the osmium in this system likely prevents re-oxidation by NMO, thus trapping the osmium catalyst and halting the catalytic cycle.

These observations led us to examine the Sharpless asymmetric dihydroxylation (SAD), where conditions allow for hydrolysis of the osmate ester before reoxidation. ${ }^{13}$ After some modification of the SAD conditions (see Supporting Information), separable isomers of 8-anti and 8syn were isolated in excellent yield and the geometry of dihydroxylation was confirmed by X-ray crystallography (Scheme 2).

Scheme 2. Dihydroxylation
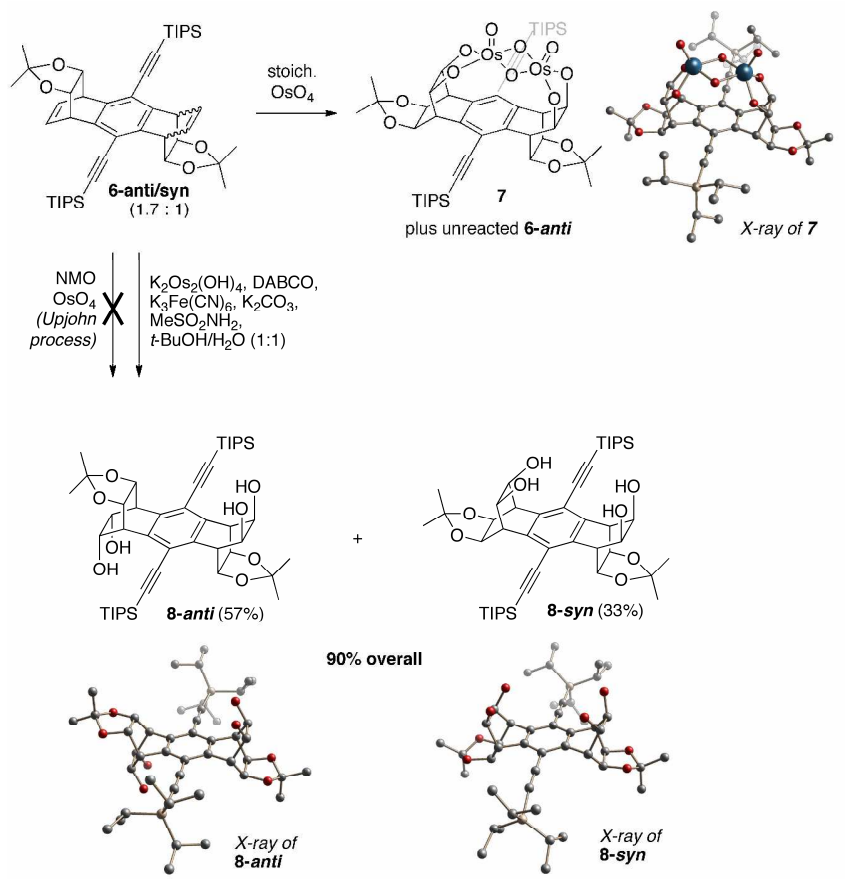

Global deprotection of 8-anti (see Supporting Information for 8-syn) with $\mathrm{BCl}_{3}$ to remove the acetonide groups followed by TBAF to remove the TIPS groups provided 1-anti (Scheme 3). Unfortunately, homopolymerization of 1-anti using palladium mediated oxidative homocoupling of acetylenes ${ }^{14}$ was not possible and only insoluble material could be isolated.

Scheme 3. Deprotection and polymerization
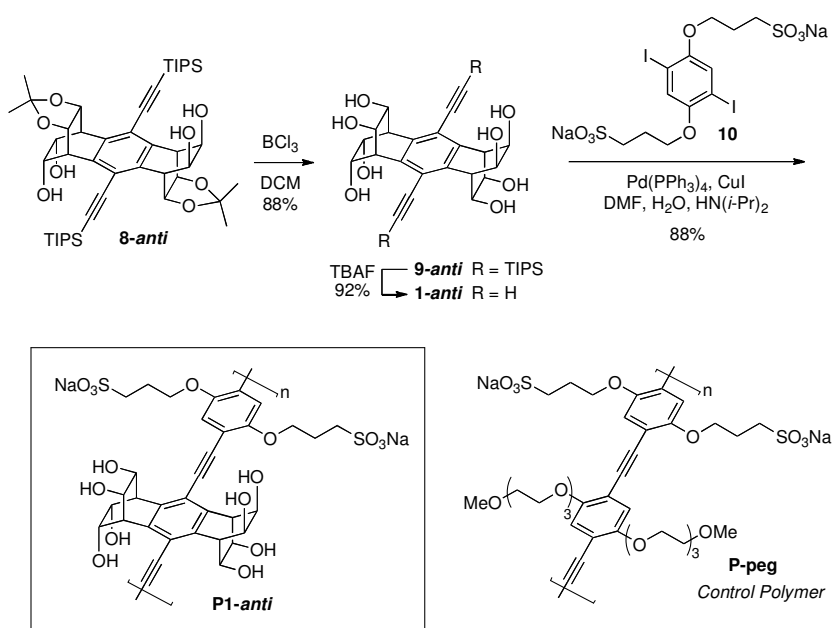
Attempts to polymerize diol protected versions of 1-anti and then deprotect after polymerization also failed to yield water soluble homopolymers. These observations suggest the rigid structure of 1-anti may not provide enough favorable entropic interactions with water to produce a soluble homopolymer. Copolymerization however, with the sulfonated diiodide $\mathbf{1 0}^{3 \mathrm{a}, 15}$ by Sonogashira polymerization produced high molecular weight $\left(\mathrm{M}_{\mathrm{n}}=14,500\right.$, PDI $=1.7$, $\mathrm{DP}=18)$ and highly water-soluble $(>8 \mathrm{mg} / \mathrm{mL})$ polymers in good yield.
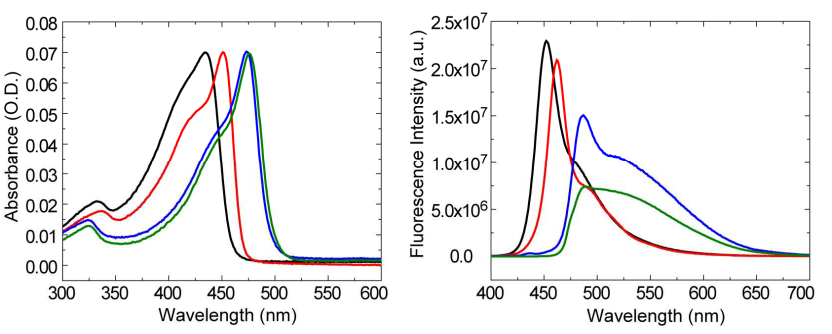

Figure 2. UV-vis absorbance and fluorescence spectra of P1-anti in water (black); P1-anti in 1X PBS (red); P-peg in water (blue); P-peg in $1 \mathrm{X}$ PBS (green).

The immediate effects of incorporating a monomer such as 1-anti with its non-compliant three dimensional architecture can be seen in Figure 2. The emission characteristics of P1-anti in comparison to an analogous control polymer (P-peg) ${ }^{5 a}$ lacking a deaggregating structure $^{16}$ is evident by the sharper emission features. Further, sensing of biological analytes will likely not take place in pure water but in higher ionic strength solutions like phosphate buffered saline. Indeed, P1-anti shows the same sharp emission features in $1 \mathrm{X}$ PBS with a quantum yield within the error of measurement (Table 1). The control polymer however, shows a complete loss of emission features, consisetnt with aggregate formation. Peak analysis data in Table 1 shows numerically what is visually represented in Figure 2. The presence of 1-anti (P1-anti) produces distinctly sharper fluorescence signals with visible vibrational features.

Table 1. Peak analysis from Figure 2

\begin{tabular}{|c|c|c|c|c|}
\hline & $\Phi_{\mathrm{F}}$ & peak height $^{\mathrm{a}}$ & FWHM $^{\mathrm{a}, \mathrm{b}}$ & ratio $^{c}$ \\
\hline P1-anti, water & $19 \%$ & 41.81 & 32.50 & 1.30 \\
\hline P1-anti, 1X PBS & $17 \%$ & 36.99 & 24.82 & 1.50 \\
\hline P-peg, water & $19 \%$ & 22.10 & 92.47 & 0.24 \\
\hline P-peg, $1 \mathrm{X}$ PBS & $12 \%$ & 10.86 & 100.29 & 0.11 \\
\hline P1-anti, water:glycerol ${ }^{\mathrm{d}}$ & $49 \%$ & 143.7 & 28.48 & 5.04 \\
\hline
\end{tabular}

Interestingly, despite evidence for the deaggregating effects of P1-anti, there is not an observed increase in quantum yield often seen when bulky side chains are used. It may be that in addition to deaggregation, bulky side chains might also serve to rigidify the polymer back bone through intrachain steric interactions. To test this, P1-anti was dissolved in 1:1 water:glycerol. This higher viscosity solution increased the quantum yield of P1-anti to $49 \%$ relative to $19 \%$ in pure water (Table 1) indicating that chain rigidification may be playing a role (see Supporting Information for spectra).

In summary, we have developed an expedient synthesis of monomer 1-anti (and 1-syn, see Supporting Information). Further, the hydrophilic three-dimensional structure of 1anti was shown to promote deaggregation when incorporated into a CPE and improved spectral properties were observed in both water and $1 \mathrm{X}$ PBS. Work towards observing interpolymer energy transfer for sensing applications is underway.

Acknowledgment Financial support for this work was provided by the Natural Science and Engineering Council of Canada (NSERC). The authors also thank Dr. Dahui Zhao for the synthesis of compound 4.

Supporting Information Available Experimental procedures and characterization data. This material is available free of charge via the Internet at http://pubs.acs.org.

(1) (a) Thomas, S. W.; Joly, G. D.; Swager, T. M. Chem. Rev. 2007, 107, 1339. (b) Satrijo, A.; Swager, T. M. J. Am. Chem. Soc. 2007, 129 16020. (c) Wosnick, J. H.; Mello, C. M.; Swager, T. M. J. Am. Chem. Soc. 2005, 127, 3400. (d) Gaylord, B. S.; Heeger, A. J.; Bazan, G. C. Proc. Natl. Acad. Sci. U.S.A. 2002, 99, 10954. (e) Wang, D.; Gong, X. Heeger, P. S.; Rininsland, F.; Bazan, G. C.; Heeger, A. J. Proc. Natl. Acad. Sci. U.S.A. 2002, 99, 49. (f) Wang, S.; Gaylord, B. S.; Bazan, G. C. J. Am. Chem. Soc. 2004, 126, 5446. (g) Kumaraswamy, S.; Bergstedt, T.; Shi, X.; Rininsland, F.; Kushon, S.; Xia, W.; Ley, K.; Achyuthan, K.; McBranch, D.; Whitten, D. Proc. Natl. Acad. Sci. U.S.A. 2004, 101, 7511. (h) Phillips, R. L.; Miranda, O. R.; You, C. C.; Rotello, V. M.; Bunz, U. H. F. Angew. Chem. Int. Ed. 2008, 47, 2590. (i) You, C. C.; Miranda, O. R.; Gider, B.; Ghosh, P. S.; Kim, I. B.; Erdogan, B.; Krovi, S. A.; Bunz, U. H. F.; Rotello, V. M. Nat. Nanotechnol. 2007, 2, 318. (j) Yang, C. Y.; Pinto, M.; Schanze, K.; Tan, W. Angew. Chem. Int. Ed. 2005, 44, 2572. (k) Pinto, M. R.; Schanze, K. S. Proc. Natl. Acad. Sci. USA 2004, 101, 7505. (1) Xu, H.; Wu, H.; Huang, F.; Song, S.; Li, W.; Cao, Y.; Fan, C. Nucleic Acids Res. 2005, 33, e83. (m) Ho, H. A.; Najari, A.; Leclerc, M. Acc. Chem. Res. 2008, 41, 168. (n) Ho, H. A.; Boissinot, M.; Bergeron, M. G.; Corbeil, G.; Doré, K.; Boudreau, D.; Leclerc, M. Angew. Chem. Int. Ed. 2002, 41, 1548. (o) Nilsson, K. P. R.; Inganäs, O. Nat. Mater. 2003, 2, 419. (p) Sigurdson, C. J.; Nilsson, K. P. R.; Hornemänn, S.; Manco, G.; Polymenidou, M.; Schwarz, P.; Leclerc, M.; Hammarstrom, P.; Wüthrich, K.; Aguzzi, A. Nat. Methods 2007, 4, 1023. (q) Li, C.; Numata, M.; Takeuchi, M.; Shinkai, S. Angew. Chem. Int. Ed. 2005, 44, 6371. (r) Feng, F.; Wang, H.; Han, L.; Wang, S. J. Am. Chem. Soc. 2008, 130, 11338. (s) Feng, F.; Tang, Y.; Wang, S.; Li, Y.; Zhu, D. Angew. Chem. Int. Ed. 2007, 46, 7882. (t) Tang, Y.; Feng, F.; He, F.; Wang, S.; Li, Y.; Zhu, D. J. Am. Chem. Soc. 2006, 128, 14972. (u) An, L.; Liu, L.; Wang, S.; Bazan, G. C. Angew. Chem. Int. Ed. 2009, 48, 4372.

(2) Swager, T. M. Acc. Chem. Res. 1998, 31, 201.

(3) (a) Tan, C.; Pinto, M. R.; Schanze, K. S. Chem. Commun. 2002, 446 (b) Tan, C.; Alas, E.; Müller, J. G.; Pinto, M. R.; Kleiman, V. D.; Schanze, K. S. J. Am. Chem. Soc. 2004, 126, 13685. (c) Chen, L.; McBranch, D. W.; Wang, H. L.; Helgeson, R.; Wudl, F.; Whitten, D. G. Proc. Natl. Acad. Sci. U.S.A. 1999, 96, 12287.

(4) For a review see: Frampton, M. J.; Anderson, H. L. Angew. Chem. Int. Ed. 2007, 46, 1028.

(5) (a) Lee, K.; Cho, J. C.; DeHeck, J.; Kim, J. Chem. Commun. 2006, 1983. (b) Khan, A.; Müller, S.; Hecht, S. Chem. Commun. 2005, 584. (c) Jiang, D. L.; Choi, C. K.; Honda, K.; Li, W. S.; Yuzawa, T.; Aida, T. J. Am. Chem. Soc. 2004, 126, 12084. (d) Kuroda, K.; Swager, T. M. Chem. Commun. 2003, 26. (e) Terao, J.; Tsuda, S.; Tanaka, Y.; Okoshi, K.; Fujihara, T.; Tsuji, Y.; Kambe, N. J. Am. Chem. Soc. 2009, 131, 16004. 
(f) Terao, J.; Tanaka, Y.; Tsuda, S.; Kambe, N.; Taniguchi, M.; Kawai, T.; Saeki, A.; Seki, Shu J. Am. Chem. Soc. 10.1021/ja908783f.

(6) Swager, T. M. Acc. Chem. Res. 2008, 41, 1181.

(7) Bowles, D. M.; Palmer, G. J.; Landis, C. A.; Scott, J. L.; Anthony, J. E. Tetrahedron 2001, 57, 3753.

(8) (a) Hart, H.; Lai, C.; Nwokogu, G. C.; Shamouilian, S. Tetrahedron 1987, 43, 5203. (b) Chen, C. L.; Sparks, S. M.; Martin, S. F. J. Am. Chem. Soc. 2006, 128, 13696.

(9) (a) Baran, A.; Seçen, H.; Balci, M. Synthesis 2003, 1500. (b) Yang, N. C. C.; Chen, M. J.; Chen, P. J. Am. Chem. Soc. 1984, 106, 7310

(10) VanRheenen, V.; Kelly, R. C.; Cha, D. Y. Tetrahedron Lett. 1976, 1973.

(11) Dupau, P.; Epple, R.; Thomas, A. A.; Fokin, V. V.; Sharpless, K. B. Adv. Synth. Catal. 2002, 344, 421.

(12) (a) Phillips, F. L.; Skapski, A. C. J. Chem. Soc., Dalton Trans. 1975 2586. (b) Casey, C. P. J. Chem. Soc., Chem. Commun. 1983, 126. (c) Cartwright, B. A.; Griffith, W. P.; Schröder, M.; Skapski, A. C. J. Chem. Soc., Chem. Commun. 1978, 853. (d) Cleare, M. J.; Hydes, P. C.; Griffith, W. P.; Wright, M. J. J. Chem. Soc,. Dalton Trans. 1977, 941. (e) Marzilli, L. G.; Hanson, B. E.; Kistenmacher, T. J.; Epps, L. A.; Stewart, R. C. Inorg. Chem. 1976, 15, 1661 .

(13) Kolb, H. C.; VanNieuwenhze, M. S.; Sharpless, K. B. Chem. Rev. 1994, 94, 2483

(14) Williams, V. E.; Swager, T. M. J. Polym. Sci., Part A: Polym. Chem. 2000, $38,4669$.

(15) Chen, W.; Joly, A. G.; Malm, J. O.; Bovin, J. O.; Wang, S. J. Phys. Chem. B. 2003, 107, 6544.

(16) CPE copolymers with $\mathbf{2}$ are not readily soluble in water, see Zheng, J.; Swager, T. M. Chem. Commun. 2004, 2798. 